\title{
Parasitic Contamination of Drinking Water and Egyptian Standards for Parasites in Drinking Water
}

\author{
Wafaa M. Hikal1,2 \\ ${ }^{1}$ Department of Biology, Faculty of Science, University of Tabuk, Tabuk, KSA \\ ${ }^{2}$ Water Pollution Research Department, Environmental Research Division, National Research Centre, Giza, Egypt \\ Email: wafaahikal@gmail.com
}

How to cite this paper: Hikal, W.M. (2020) Parasitic Contamination of Drinking Water and Egyptian Standards for Parasites in Drinking Water. Open Journal of Ecology, 10, 1-21.

https://doi.org/10.4236/oje.2020.101001

Received: November 30, 2019

Accepted: January 3, 2020

Published: January 6, 2020

Copyright $\odot 2020$ by author(s) and Scientific Research Publishing Inc. This work is licensed under the Creative Commons Attribution International License (CC BY 4.0).

http://creativecommons.org/licenses/by/4.0/

\begin{abstract}
Water is life and access to clean drinking water is a fundamental human right. For human health, drinking water standards and guidelines have been developed to ensure their quality. Waterborne parasites are a great challenge and cause many diseases for humans. Thus, continuous monitoring of drinking water from the competent authorities in search of pollutants is required. The safety of drinking water for the growing population can be ensured by the correct use of water treatment technologies. Cryptosporidium is the first parasite to cause concern to health officials in the world. Also, Naegleria fowleri causes fatal cerebral infection, Acanthamoeba species that cause both cerebral and corneal disease; and Giardia which has heightened world concerns because of its severity. This study is based on highlighting on drinking water quality guidelines and standards published by the World Health Organization and some countries, especially Egypt. A growing concern globally after the scientists revealed the effects of polluted drinking water. So, a large number of the population is at risk of water pollution for the purpose of human access to clean drinking water and other uses.
\end{abstract}

\section{Keywords}

Drinking Water, Standards, Acanthamoeba, Cryptosporidium, Giardia, Naegleria

\section{Introduction}

Water is essential for human life. The world health organization has considered access to safe drinking water a basic human right to maintain human health. Therefore available drinking water must meet drinking water quality standards 
and does not pose any health risk over a life time [1]. Tap water and also potable water is drinking water that is provided for home use. It is clean and safe to drink or to use in food preparation and others [2]. Consumption of drinking water contaminated is one of the biggest threats to public health. Globally, about 1 to 2 billion people are suffering from a lack of safe drinking water and 30,000 people die every week from contaminated water, more than people died as a result of the war [3] [4]. The sources of drinking water available to the population are diverse and include; water supply network, surface water such as (lakes, rivers, streams, glaciers), groundwater sources (springs or wells) or precipitation (rain, snow) [1]. Springs are often used as sources for bottled waters [5]. Tap water, delivered by domestic water systems refers to water piped to homes and delivered to a tap or spigot. To ensure the safe consumption of any water source, it must receive appropriate treatment and be subject to drinking water quality standards [6]. Water quality is generally assessed by several aspects that affect its quality including; microbiological, physical, chemical (inorganic chemicals, organic compounds) and radiological characteristics and the effect of these characteristics on public health. Detailed water analyses should be carried out to ensure that drinking water should be clear, free from offensive taste or smell, free from chemicals or compounds contaminations that may have adverse effects on health or harmful in long term and free from pathogenic organisms. Most of the serious problems in drinking water especially in developing countries are mainly due to microbiological and chemical contaminations and microbial quality is usually the most important especially pathogenic parasitic contaminants [1]. Egypt is one of the middle-income countries that aim to improve the water supply to the households [7]. However, the delivery of water quality remains a constraint and challenge [8] [9]. Whereas, the delivery of improved water supplies is intended to reduce the burden of disease associated with the consumption of contaminated water, much of which is attributable to diarrheal disease [10] [11]. Government officials have blamed numerous outbreaks of diarrhea in recent years on water that was contaminated by poor pipe quality [8] [9], as shown by the high bacterial counts at the water use point compared to the treated sites [9], however, a scant study on drinking water contamination is a concern because of the poor quality of the pipes connecting households to water treatment facilities in Egypt [8] [9]. Studies show that improvements in water quality and increased water supply are effective in reducing morbidity caused by diarrhea [12] [13] [14] [15] [16]. This has been confirmed by a number of studies in Egypt that access to better quality water is associated with lower child mortality [17] [18]. In a $2017 \mathrm{WHO/UNICEF}$ report [19], 29\% of the world's population ( 2.1 billion people) in 2015 lacked access to safe drinking water in their homes and therefore more than 3.4 million deaths from water-borne diseases, making them the cause of disease and death around the world. Most of these deaths are young children, about 4000 children a day. About half of the developing world's population suffers from some type of water-borne disease. From 2013 to 2014, water-borne diseases caused 289 illnesses, 108 hospitaliza- 
tions and 17 deaths in the United States. Pathogenic bacteria, viruses and parasites are the most common health risks associated with drinking water. Drinking water has a range of risks in the form of pathogenic parasites (such as protozoa and helminths) and if these parasites are not properly disposed of, they can pose a threat to public health and the environment [19] [20]. The highest priority and goal that all countries seek with the world health organization (WHO) by adopting standards and laws to keep water safe and clean to prevent the spread of the disease as water-borne diseases are the leading cause of death worldwide [7]. In this study conducted in Egypt in 2019, shed light on the risks of contamination of drinking water with pathogenic parasites and focus on some pathogenic parasites such as Acanthamoeba-with a list of some of the standards and laws available and adopted by some countries with emphasis on the Egyptian specifications of drinking water regarding the contaminated parasites of drinking water.

\section{Waterborne Parasites}

According to the safe drinking water act, the presence of any physical, chemical, biological or radiological substance or matter in drinking water means water contamination. These contaminants are harmful if their presence in water exceeds the permissible limits and poses a health hazard. The presence of organisms in water means biological contaminants. They may be called microbiological contaminants or microbes contaminants, such as viruses, bacteria and parasites [21]. Biological contamination is the most common and widespread health risk associated with drinking water, whether direct or indirect with the micro-organisms contained in faeces and by human or animal excreta. There are many different organisms have been identified as pathogens and can contaminate drinking water such as bacteria, virus and parasites, whereas, more than five million people die each year from contaminated water, of which $50 \%$ are microbial intestinal diseases such as cholera, which are the leading cause of death. Children under five years are most affected by waterborne microbial diseases. So, drinking water should be free from pathogenic microorganisms [1]. Water-borne diseases are diseases that are transmitted to humans or animals through water, which usually contain a proportion of pathogenic microorganisms. According to the World Health Organization, $1.4 \%$ of people who have suffer from diarrhea caused by contaminated water. Contaminated water (especially groundwater) kills 1.8 million people every year [22]. It is not easy to provide evidence of biological hazards especially with respect to protozoans and worms, as a result of any evidence must be subject to epidemiological considerations relating to two things of which the presence of many parasites with geographical distribution, and most waterborne parasites are transmitted in other ways, such as food and the direct spread from feces to the mouth [23]. According to the definition of the parasite by CDC [24], is the living organism that lives in or on a host organism and gets its food from or at the expense of its host. There are three types of parasites; one of them is unicellular protozoa that live in intestine, blood or tissue. 
The second is parasitic worms, such as tapeworms, round worms and finally external parasites like lice and mites.

\section{Sources of Parasites Spread}

Drinking contaminated water and eating unclean foods or undercooked meat is one of the most common sources of parasites. Eating these meats can lead to intestinal tapeworms. Drinking contaminated water can lead to scabies, a skin disease. Very strong and contagious, accompanied by severe itching and a rash that looks like pimples [25]. There are many diseases that cause unexplained weight loss, and parasitic infection is one of them. Tapeworms cause weight loss because a large intestinal worm is eating your food, and weight loss is often accompanied by anorexia and upset stomach. The most common symptoms associated with parasites are those that mimic irritable bowel syndrome. Intestinal parasites may cause abdominal pain, bloating, diarrhea, itching, bowel obstruction and anemia. No symptoms may be one of the symptoms. It's frightening, but it's true. Some parasitic infections produce zero symptoms. Experts and doctors recommend a series of blood tests, fecal tests, X-rays, or colonoscopy. Some may be tired but worth it. That parasites cause a very serious disease. Worms can also grow in the human body up to 35 centimeters in length and lead to intestinal obstruction. Humans suffer from a large number of parasites, which cause some of the most important diseases in the world. Therefore, waterborne protozoan pathogens always receive attention because they cause infection and disease in humans and animals. Thus, controlling of waterborne transmission is a real challenge, because it is difficult in some pathogens to remove their eggs, oocysts or cysts by the process of filtration or disinfection due to the fact that it is resistant to the disinfection process [1].

\subsection{Protozoa}

Protozoa are free living and single-celled organisms that have the ability to reproduce in humans, allowing them to survive and develop, Where they live in the intestines of humans and transmitted from one human to another either through a fecal-oral route (contaminated water, food or person-to-person contact). But protozoa, which live in human blood or tissue are transmitted to another human by an arthropod vector (mosquito or sand fly) [24].

\subsection{Helminthes}

Helminthes are visible to the eye in their adult stages and multicellular organisms that may be free-living or parasitic. Helminthes in their adult form cannot reproduce within a human [24]. Of human helminthes there are three groups: 1) Flatworms (Platyhelminthes) like trematodes cestodes (tapeworms) and (flukes); 2) Thorny-headed worms (acanthocephalans), the acanthocephalans are intermediate between the cestodes and nematodes, where adult forms are found in the gastrointestinal tract; 3) Roundworms (nematodes), adult forms of nema- 
todes found in the gastrointestinal tract, lymphatic system, blood or subcutaneous tissues.

Several species of protozoan pathogens may be transmitted to humans through the drinking water route associated with many health risks. The following protozoa and worms transmitted by drinking water in Table 1(a) and Table 1(b) and Figure 1 has been identified as waterborne pathogens [1] [16] [26].

\section{Pathogenic Protozoan from Drinking Water in Egypt}

In Egypt, studies have confirmed the presence and isolation of many pathogenic parasites transmitted through drinking water, also, many studies have isolation and definition of these parasites from patients, as shown in Table 2(a) and Table 2(b). According to the results obtained in Egypt; Table 2(a) shows waterborne parasites during the last five years of 2015-2019 and these parasites are very similar to those in Table 1(a) approved by WHO, the parasites in Table 2(b), no data available for their existing in the last five years, besides a few studies on the presence and isolation of patient cases.

On the other hand, the available studies have not proved isolation of the following parasites from drinking water; while some reports in Egypt have been isolated these parasites from patients which could be identified as follows; Fasciola hepatica, Trichuris trichiura, Trichostrongylus sp, H. heterophyes, Hymenolepis diminuta, Hymenolepis nana, Taenia saginata [34], Schistosoma mansoni [44], Schistosoma haematobium [45], and Taenia solium [46]. In this review, we will highlight on some parasite pathogens based on the abundance of information about the outbreak of the disease caused by the parasite and the severity of the disease, in addition to the difficulty of eliminating the parasite and it's widespread in the aquatic environment. Two parasites of free-living amoebae have been responsible for serious disease. Cerebral infection by Naegleria fowleri is strictly water-borne, and although rare is usually fatal. Acanthamoeba species cause both cerebral and corneal disease. Enteric protozoa may be found in water following direct or indirect contamination with human and animals' faeces. Two enteric protozoa causing severe disruption are Cryptosporidium parvum and Giardia.

\subsection{Naegleria fowleri}

Brain-eating amoeba is one of the rare parasites that enter the brain through the nose and consume its cells. This rare type of amoeba is called Naegleria fowleri because ordinary amoebas are a part of the natural system that feeds on bacteria and live in warm ponds and lakes. When people swim in warm, fresh water during the summer, people inhale through their noses naturally, making them reach the brain directly. These amoebas cause headaches, stiff neck and vomiting. These symptoms develop dangerously as the amoeba develops inside the brain and eventually reaches coma and then death [47]. Brain-eating amoebas live in freshwater or water that does not have minimal chlorination. It is not common to have amoeba detection tests, especially in summer when the water is 
Table 1. (a) Parasites transmitted through drinking water (WHO 2017); (b) Parasites transmission through drinking-water has been proposed, but for which evidence is inconclusive or lacking (WHO 2017).

(a)

\begin{tabular}{ccccc}
\hline Protozoa: & Species & $\begin{array}{c}\text { Resistance to } \\
\text { chlorine }\end{array}$ & $\begin{array}{c}\text { Health } \\
\text { significance }\end{array}$ & $\begin{array}{c}\text { Relative } \\
\text { infectivity }\end{array}$ \\
\hline Acanthamoeba & A. culbertsoni & High & High & High \\
Cryptosporidium & C. hominis/parvum & High & High & High \\
Cyclospora & C. cayetanensis & High & High & High \\
Entamoeba & E. histolytica & High & High & High \\
Giardia & G. intestinalis & High & High & High \\
Naegleria & N. fowleri & Low & High & Moderate \\
\hline \multirow{2}{*}{ Dracunculus } & D. medinensis & Helminthes. & & \\
\hline
\end{tabular}

(b)

\begin{tabular}{cc}
\hline Protozoa: & Resistance to chlorine \\
\hline Balantidium coli & High \\
Blastocystis hominis & High \\
Isospora belli & High \\
Microsporidia & Moderate \\
Toxoplasma gondii & High \\
\hline Helminthes. & High \\
\hline Fasciola spp. & High \\
\hline Free-living nematodes (other than Dracunculus medinensis) & Moderate \\
\hline
\end{tabular}

warm and has an amoeba growth environment. Only 4 people in the US out of 145 have survived infection from 1962 to 2018 [48].

\subsection{Acanthamoeba}

Acanthamoeba is a genus of protozoa. It is a microscopic amoeba widespread in the surrounding environment, where it is found in water in nature and treated water in ponds and heated baths, soil, air (in cooling towers, or heating, adaptation and ventilation systems), drainage systems, drinking water distribution systems especially in the heads shower and bathrooms. Most people will be exposed at some stage to this amoeba without any medical condition, but Acanthamoeba is capable of causing different infections in humans. Keratitis is an eye disease that usually affects healthy people and can lead to permanent visual impairment or blindness. Granulomatous amoebic encephalitis is a serious disease of the brain and spinal cord, usually in people with a weakened immune system. 


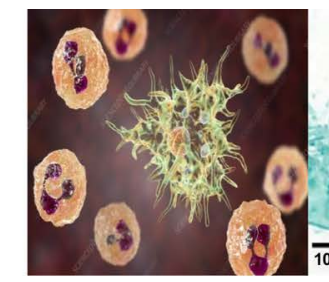

Acanthamoeba

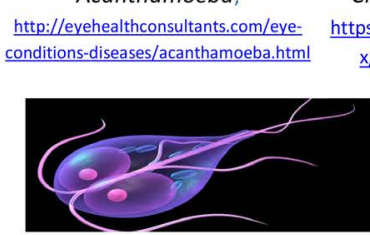

Giardia lambilia; https://www.thesprucepets.com

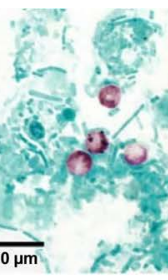

Cryptosporidium Cryptosporidium; ps://www.cdc.gov/dp x/cryptosporidiosis

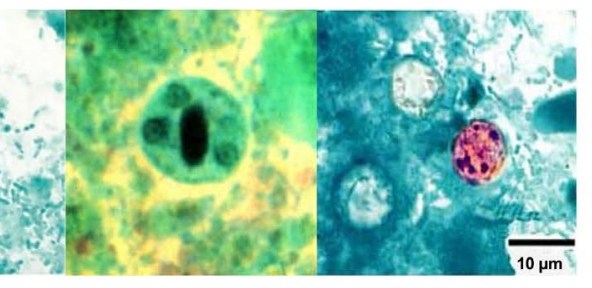

Cyclospora;

Entamoeba

DPDx, the CDC

parasitology website LCyclospora cavetanensis https://en.wikipedia.org/wiki

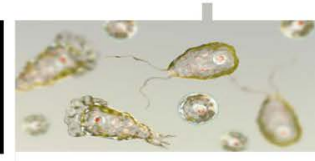

Naegleria fowleri; www.biospace.com

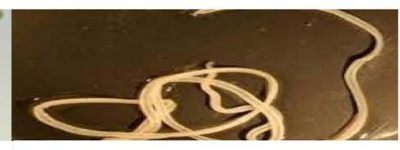

Dracunculus;

https://steemit.com/health/@abbevcity/resear ch-on-dracunculus-medinensis-guinea-worm

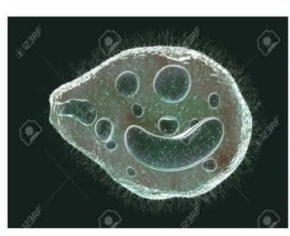

Balantidium coli https://www.canstockphot m/balantidium-coli

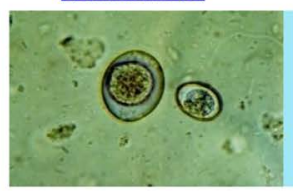

Isospora belli https://alchetron.com//sospora

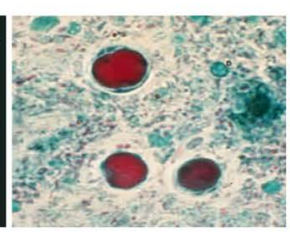

Blastocyst hominis ttps://www.cdc. gov/dpdx/blastocy

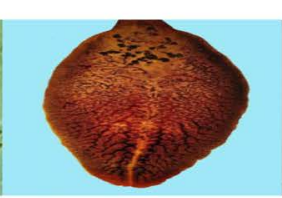

Fasciola spp https://www.cdc.qov/dpdx/f $\underline{\text { ascioliasis }}$

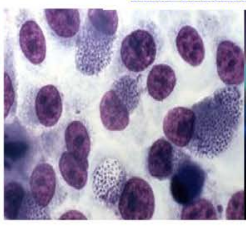

Microsporidia tistps://microbewiki.kenyon.e du/index.php/Microsporidia

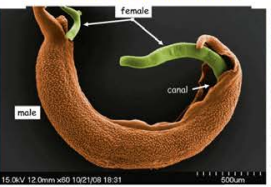

Schistosoma Morand et al.2012

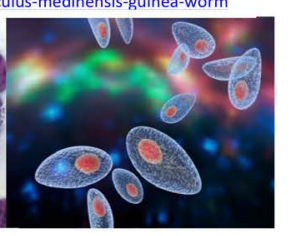

Toxoplasma gondii https://www.intechopen.com/ books/toxoplasmosis

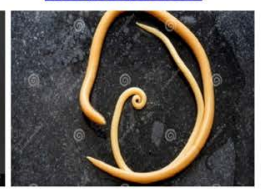

Ascaris

https://www.dreamstime.com/ascariasisdisease-caused-parasitic-roundwormascaris-lumbricoides-education

Figure 1. Examples of parasites transmitted during drinking water.

Keratitis occur when Acanthamoeba reach the eye of contact lens wearers, for example, when they wash the lenses under tap water or when they do not clean them adequately or wear them for a long time or while swimming. Pain is usually four to five weeks after the infection has occurred, where Acanthamoeba has already damaged the nerves of the eye. If the infection is detected early, the patient should continue to receive treatment for more than a year. Acanthamoeba infection can cause persistent visual impairment three weeks after it has occurred, and may even lead to complete vision loss [49].

\section{Granulomatous Amoebic Encephalitis}

It is a very rare infection that can infect the skin, sinuses, brain and other organs of the body so the infection can cause a wide range of symptoms of the disease. Diagnosis can be difficult and often fatal. Although early diagnosis and treatment may increase the chances of survival, the death rate is more than 95\% [24]. Symptoms of granulomatous amoebic encephalitis: headache, stiff neck or head and neck pain with neck movement, sensitivity to light, nausea, vomiting, tired, low temperature fever, behavioral changes, seizures, weight loss, partial paralysis, difficulties in pronunciation and a difficulty walking [50]. 
Table 2. (a) Parasites transmitted through drinking water (2015-2019); (b) Parasites transmitted through drinking water before (2015).

(a)

\begin{tabular}{ccc}
\hline Pathogen & Drinking Water & Case Reports (Patients) \\
\hline Protozoa & \multicolumn{2}{c}{ References } \\
\hline Acanthamoeba spp & Taher et al. [27] & Taher et al. [27] \\
Cryptosporidium hominis/parvum & Elfadaly et al. [28] & Shehata et al. [32] \\
Entamoeba histolytica & Elfadaly et al. [28] & El-Badry et al. [33] \\
Giardia intestinalis & Elfadaly et al. [28] & Shehata et al. [32] \\
Naegleria fowleri & Abd El Wahab et al. [29] & \\
Toxoplasma gondii & Elfadaly et al. [28] & Shehata et al. [32] \\
\hline Strongyloides stercoralis & Helminthes & El-Shazly et al. [34] \\
Enterobius vermicularis & El-Badry et al. [30] & El-Shazly et al. [34] \\
\hline
\end{tabular}

(b)

\begin{tabular}{ccc}
\hline Pathogen & Drinking Water & Case Reports (Patients) \\
\hline Protozoa & \multicolumn{2}{c}{ References } \\
\hline Cyclospora cayetanensis & Khalifa et al. [35] & Shehata et al. [32] \\
Blastocystis hominis & Khalifa et al. [35] & Shehata et al. [32] \\
Microsporidia & Amer [36] & Shehata et al. [32] \\
Balantidium coli & Amer [36] & Abaza et al. [40] \\
Sarcocystis lindemanni & Amer [36] & Abdel Mawla [41] \\
Cystoisospora belli & Elshazly et al. [37] & Shehata et al. [32] \\
Isospora belli & Elshazly et al. [37] & Abdel-Hafeez et al. [42] \\
Isospora hominis & Elshazly et al. [37] & El-Shazly et al. [34] \\
\hline Capillaria philippinensis & Helminthes & \\
Ancylostoma duodenale & Attia et al. [38] & Youssef et al. [43] \\
Ascaris lumbricoides & Miller et al. [39] & El-Shazly et al. [34] \\
\hline
\end{tabular}

\subsection{Cryptosporidium}

Cryptosporidiosis is the diarrheal disease that causes by a microscopic parasite called Cryptosporidium. Both the parasite and the disease are commonly known as "crypto". There are many species of Cryptosporidium that infect animals, some of which also infect humans. The parasite is protected by an outer shell that allows it to survive outside the body for long periods of time and makes it very tolerant to chlorine disinfection. While this parasite can be spread in several different ways, water (drinking water and recreational water) is the most common way to spread the parasite. Cryptosporidium is a leading cause of waterborne disease among humans in the United States [1]. Symptoms of cryptospo- 
ridiosis generally begin 2 to 10 days (average 7 days) after becoming infected with the parasite. The most common symptom of cryptosporidiosis is watery diarrhea. Symptoms include: Stomach cramps or pain, dehydration, nausea, vomiting, fever and weight loss [24].

\subsection{Giardia Lamblia}

Giardiasis is one of the most common diseases transmitted by contaminated water, causing chronic diarrhea and malabsorption that make the patient in a deplorable state. According to the World Health Organization, diarrhea is the leading cause of death among children under the age of five, and Giardia is a widespread parasitic infection and is the most prevalent in the world, especially in tropical regions and poor countries suffering from poor health and living conditions. Children under the age of five appear to be the most vulnerable. Fifteen to 30 percent of children in developing countries under the age of 10 suffer from giardiasis. Infection with the parasite (in the form of invisible cysts by the naked eye) occurs through drinking contaminated water, eating contaminated food. Giardia parasite enters the body through the mouth to continue its way through the esophagus and then crosses the stomach without being affected by its juices. It settles in the duodenum attached to its inner lining and suffers from malabsorption syndrome in which nutrients, especially mineral salts and vitamins are wasted. If the Giardia parasite passes through the large intestine (colon), it surrounds itself with a thick bag that protects it from external conditions. The majority of people with giardiasis do not have any symptoms. The rest of them have giardiasis with a bundle of symptoms that vary from person to person. This diarrhea includes foul odor, excessive gases, upper abdominal pain, frequent burping, and lack of appetite. Violent vomiting occurs, but it is rare [24].

\section{Regulation of Drinking Water}

Since ancient times, there are criteria for drinking water quality when the taste and smell of water change, and the treatment methods were boiling water or exposure to sunlight, filtering through coal to remove suspended substances (coagulation) during the Greek civilization. This was followed by the establishment of the first water supply network in Rome, Greece, Carthage and Egypt during the Roman civilization and a simple progress in treatment by filtering water through cloth [51]. In Scotland in 1804, the first public water facility was built to supply the city with filtered water. Sand filtration was regularly used in Europe. At this time, scientists realized that diseases such as dysentery, cholera and typhoid could be spread by pathogens in the public water supply [51], and the microbiologist Antonie van Leeuwenhoek in 1676 for his discovery of microorganisms in water. But these microorganisms are not linked to waterborne diseases. In 1855, epidemiologist Dr. John Snow proved that cholera was a water-borne disease, and both scientists (Louis Pasteur, Joseph Lister and Robert Koch) confirmed the microorganisms transmitted through water [51] [52]. By the begin- 
ning of the 20th century, the main concern in water treatment was the elimination of pathogenic microbes using filtration. Disinfectants were used and chlorination became essential for the elimination of pathogenic microbes in water. United States of America was first used chlorine in 1908 as a major disinfectant and at the same time Europeans used ozone in treatment [51].

\section{International Standards of Drinking Water}

The World Health Organization (WHO) has been active in issuing and developing water quality standards through its guidance. The first published report of drinking water quality guidelines and testing methods in 1958 and European drinking water standards in 1961. Guidelines for drinking water quality were issued in 1963 by WHO, followed by several guidelines for drinking water quality and development. In 1974, the United States established the US Environmental Protection Agency (EPA), which is responsible for setting drinking water standards as a result of growing concern about water-borne diseases [1] [53]. The drinking water quality guidelines of the World Health Organization (WHO) cover various aspects that cause harm to health, including physical, chemical, biological and radiological aspects. The World Health Organization (WHO) provides guidance to all the international community for use by governments to set their own national standards [54]. Consumption of drinking water contaminated with microbes is one of the biggest threats to public health. WHO has identified several properties that characterize pathogens transmitted by drinking water which are called waterborne pathogens [54]. There are several characteristics to judge water-borne pathogens: 1) Have the ability to grow in the environment-Cause acute and chronic diseases; 2) They often stick to suspended solids in water, and their concentration changes so that the risk of injury cannot be predicted from their average concentration in water; 3) The disease caused by exposure to the pathogens depends on the dose, invasion and virulence of the pathogen, and the immune status of person; 4) Have the ability to reproduce/multiply inside the host and can reproduce in foods, beverages, drinks or warm water systems, and this increases the risk of infection; 5) Pathogens do not show a cumulative effect unlike many chemical agents.

Protecting public health is the main objective of the World Health Organization through its guidance that is useful in providing documented basics that are useful in setting national standards for drinking water quality, health risks and impacts associated with drinking water contaminants, best options for managing drinking water and disease prevention and control. International standards drinking-water (1958) is the oldest edition, followed by the second edition in 1963, the WHO did not established guidelines for parasites. WHO recommended guidelines for parasites starting in 1971 with the development of the following editions. In 1998, the WHO did not establish any new guidelines for the parasites. In guidelines for drinking-water quality [1], the WHO established guidelines for the parasites. This edition considered many recommendations according to drinking-water safety including parasites hazards, which continue to be 
the important concern in both developing and developed countries. The following table shows the developing of drinking water standards for parasites according to WHO guidelines (Table 3 ).

\section{Egyptian Standard Specifications for Drinking Water}

Due to the health problems facing Egypt caused by pollution resulting from population activities on the various components of the environment such as air, soil, food and especially water pollution. To ensure the health of the Egyptian citizen, Law No. 27 of 1978 was issued on the public resources for drinking water and human use, and the Ministry of Health became responsible to produce guidelines for drinking water in Egypt. The first drinking water standard was adopted in 1995 [55].

The purpose of setting health standards for drinking water in Egypt is: 1) To be a guide for public health workers or officials to oversee the health of drinking water to ensure its validity; 2) The conformity of water in a country to international standards encourages international tankers such as aircraft and ships to supply water from airports and ports located in that country; 3) Encourage inbound and outbound tourism; 4) Drinking water/potable water is safe to drink or to human uses without causing health problems, and is usually supplied to the consumer either through the public network or the limited distribution network, while drinking water supplied through indoor plumbing for drink and home uses is tap water; 5) The Egyptian standards achieve the following objectives; make the water clear-free from color, palatable taste and smell-disposal of salts and harmful chemicals that limit the use of this water in human and industrial purposes such as iron, manganese, water hardness, etc. [55].

The water should be suitable for drinking, human use, industrial and food purposes. In this regard, On 11/3/1995, for the first time, decree of the Minister of Health and population No (108) regarding the standard specifications for drinking water and No (301)/1995 concerning methods of sampling water for testing to produce guidelines for drinking water in Egypt. Regarding the decision No (108) the standard specifications that must be available in potable water and domestic use, these standard specifications are divided into 5 sections: 1) Physical properties: color-taste-odour-turbidity-pH; 2) Inorganic chemicals, which have an effect on palatability and household uses such as (dissolved salts-iron-manganese-water hardness); 3) Chemicals: which have an impact on public health and are either inorganic or organic substances; 4) Inorganic Substances: Heavy metals such as lead, cadmium, mercury, nitrate, nitrite and fluorides; 5) Organic materials such as: Pesticides as well as herbicides; Organic substances other than pesticides such as phenol-disinfectants and their products-chlorinated acetic acids-halogenated acetonitriles-chlorinated alkanes-chlorinated ethane compounds-chlorinated benzenes [55].

Microbiological criteria include: Total number of bacteria; Indicators of contamination, total coliform bacteria-colon fecal bacteria-fecal streptococcus; 
Table 3. WHO drinking water guideline according to parasitic standards.

\author{
WHO 1958 \\ WHO 1963 \\ WHO 1971 Drinking-water should not contain amoebic cyst, Schistosoma spp., and Dracunculus medinensis
WHO 1984 and 1985 stages of helminthes (Dracunculus medinensis, Schistosoma mansoni, S. haematobium, S. intercalatum, Ascaris lumbricoides, Trichuris trichiura, Strongyloides stercoralts, and Ancylostoma duodenale)
WHO 1993 and 1996
Drinking-water should not contain protozoa (Giardia spp., Cryptosporidium spp., Entamoeba histolytica, and Naegleria fowleri Acanthamoeba spp., and Balantidium coli.).
Helminthes (Dracunculus medinensis, Fasciola spp., Echinococcus spp., Schistosoma mansoni, S. haematobium, S. intercalatum, Spirometra spp., Ascaris lumbricoides, Trichuris, Toxocara, Necator amencanus, Ancylostoma duodenale, Strongyloides stercoralts and Taenia solium). \\ Drinking-water should not contain protozoa (Entamoeba histolytica, Giardia spp. and Balantidium coli.) or infective
}

WHO 1998

WHO 2002

WHO 2004 and 2006

WHO 2008

WHO 2011

WHO 2017
Drinking-water should not contain protozoa (Entamoeba histolytica, and Naegleria fowleri Acanthamoeba spp., Cryptosporidium parvum, Giardia intestinalis, Cyclospora cayetanensis and Toxoplasma gondii).

Drinking-water should not contain protozoa: Acanthamoeba spp. (A. castellanii, A. polyphaga and A. culbertsoni), Giardia intestinalis, Cryptosporidium parvum, Microsporidia, Cyclospora cayetanensis, Entamoeba histolytica,

Isospora belli, Balantidium coli, Naegleria fowleri and Toxoplasma gondii).

Helminthes Fasciola spp. (F. hepatica and F. gigantica), Dracunculus medinensis Strongyloides stercoralts, Ascaris lumbricoides, Trichuris trichiura and Schistosoma spp. (S. mansoni, S. haematobium, S. intercalatum).

Drinking-water should not contain protozoa: Acanthamoeba spp. (A. castellanii, A. polyphaga and A. culbertsoni), Microsporidia, Entamoeba histolytica, Balantidium coli, Cryptosporidium parvum, Cyclospora cayetanensis, Isospora belli, Giardia intestinalis, Naegleria fowleri and Toxoplasma gondii).

Helminthes: Fasciola spp. (F. hepatica and F. gigantica), Dracunculus medinensis, Ascaris lumbricoides, Trichuris trichiura, and Schistosoma spp. (S. mansoni, S. haematobium, S. intercalatum).

Free-living nematodes hookworms (Necator americanus, Ancylostoma duodenal) and threadworms (Strongyloides stercoralis).

Drinking-water should not contain protozoa: Acanthamoeba (A. castellanii, A. polyphaga and A. culbertsoni), Cyclospora cayetanensis, Balantidium coli, Entamoeba histolytica, Cryptosporidium hominisl parvum, Giardia intestinalis, Naegleria fowleri, Blastocysts hominis, Isospora belli, Microsporidia and Toxoplasma gondii).

Helminthes: Dracunculus medinensis and Fasciola spp. (F. hepatica and F. gigantica), Ascaris lumbricoides, Trichuris trichiura, Schistosoma spp. (S. mansoni, S. haematobium, S. intercalatum).

Free-living nematodes other than (Dracunculus medinensis). Free-living nematodes hookworms (Necator americanus an Ancylostoma duodenal) and threadworms (Strongyloides stercoralis).

Drinking-water should not contain protozoa: Acanthamoeba (A. castellanii, A. polyphaga and A. culbertsoni), Cyclospora cayetanensis, Giardia intestinalis, Balantidium coli, Cryptosporidium hominis/ parvum, Entamoeba histolytica, Blastocysts hominis, Naegleria fowleri, Isospora belli, Microsporidia and Toxoplasma gondii). Helminthes: Dracunculus medinensis, Fasciola spp. (F. hepatica and F. gigantica), Ascaris lumbricoides, Trichuris trichiura, Schistosoma spp. (S. haematobium, S. intercalatum, S. japonicum, S. mekongi and S. mansoni). Free-living nematodes other than (Dracunculus medinensis). Free-living nematodes hookworms (Necator americanus and Ancylostoma duodenal) and threadworms (Strongyloides stercoralis).

Biological examination of protozoa and blue green algae; radioactive materials, including: Alpha family derivatives and Beta family derivatives [55].

With regard to biological tests, Egyptian standards specifications indicate that drinking water should be available and should be free from protozoa and all stages of pathogenic worms in accordance with Minister of Health Decree No. 
$108 / 1995$ and it was adopted on 11/3/1995. In 2007, a new decree No. 458 of 2007 [56] was issued by the Minister of Health and Population on the maximum standard specifications to be met in drinking water and domestic use and was adopted on $21 / 10 / 2007$. With regard to biological tests for parasites; there was no change, as the recommended that drinking water should be completely free of live protozoa and all stages of pathogenic worms (Table 4).

\subsection{Potable Bottled Natural Mineral Water}

Bottled natural mineral water, usually obtained from natural or etched sources, for example: rivers, springs, wells, etc. Egyptian Organization for Standardization and Quality [57] described that standards, and the preparation means to achieve their use in the plan to develop Egyptian standards with a view to upgrading to international levels and the preparation of research and studies related to international and regional organizations and others and follow-up the work of international technical committees of which the commission is a member projects to issue Egyptian specifications. In 2005, Egyptian Organization for Standardization and Quality issued Egyptian standards (ES) No. 1588 on standard specifications to be met in potable bottled natural mineral water and was adopted on 13/2/2005. The Egyptian standards (ES) No. 1588/2005 [58] recognized that potable bottled natural mineral water should be free from pathogenic microorganisms. It does not cause any health risks to the consumer. Waterborne parasites did not specify (Table 5). In 2017, a new decree No. 1588 [59] was issued by Egyptian Organization for Standardization and Quality to be met in potable bottled natural mineral water and was adopted on $2 / 5 / 2017$. With regard to biological tests for parasites; there was no change from the previous Egyptian standards (ES) No. 1588/2005 recognized that potable bottled natural mineral water should be free from primary organisms that pose a threat to health and specifically pathogenic microorganisms including parasites.

\subsection{Bottled Packaged Drinking Waters (Other than Natural Mineral Waters)}

Bottled water other than natural mineral water is water intended for human consumption and may contain naturally occurring or intentionally added minerals. It may contain naturally occurring carbon dioxide or intentionally added but does not contain sugars, sweeteners, flavor enhancers or other foodstuffs. In 2005, Egyptian Organization for Standardization and Quality issued Egyptian standards (ES) No. 1589 on standard specifications to be met in bottled packaged drinking waters (other than natural mineral waters) and was adopted on

Table 4. The maximum limit of Egyptian specifications in terms of parasites in potable water and domestic use.

\begin{tabular}{ccc}
\hline \multirow{2}{*}{ Type of examination } & \multicolumn{2}{c}{ Maximum permissible limits issued by the Minister of Health and Population } \\
\cline { 2 - 3 } & \multicolumn{1}{c}{ Old No. (108) of 1995} & Modern No. (458) of 2007 \\
\hline $\begin{array}{c}\text { When examining water } \\
\text { microscopy samples }\end{array}$ & $\begin{array}{l}\text { Examining water microscopy should be completely } \\
\text { free of protozoa and all stages of pathogenic worms }\end{array}$ & $\begin{array}{l}\text { Examining water microscopy should be completely free } \\
\text { of live protozoa and all stages of pathogenic worms }\end{array}$ \\
\hline
\end{tabular}


Table 5. The maximum limit of Egyptian specifications in terms of parasites in potable bottled natural mineral water.

\begin{tabular}{cll}
\hline \multirow{2}{*}{ Name of national regulation } & Maximum permissible limits issued by the Egyptian Organization for Standardization and Quality \\
\cline { 2 - 3 } & \multicolumn{1}{c}{2005} & 2017 \\
\hline Egyptian Standards & $\begin{array}{l}\text { Potable bottled natural mineral water should be } \\
\text { free from pathogenic microorganisms. }\end{array}$ & $\begin{array}{l}\text { Potable bottled natural mineral water should } \\
\text { be free from primary organisms that pose a }\end{array}$ \\
ES: $1588 / 2005 ; 2017$ & $\begin{array}{l}\text { It does not cause any health risks to the consumer } \\
\text { threat to health and specifically pathogenic } \\
\text { microorganisms including parasites. }\end{array}$ \\
\hline
\end{tabular}

13/2/2005. The Egyptian standards recognized that bottled packaged drinking waters (other than natural mineral waters) must be fit for human consumption and should be completely free of protozoa and any non-bacterial microorganisms. In 2007, a new Egyptian standards (ES) No. 1589 of 2007 [60] was issued by the Egyptian Organization for Standardization and Quality on standards and specifications to be met in bottled packaged drinking waters (other than natural mineral waters) and was adopted on 13/12/2007. With regard to biological tests for parasites; there was no change from the previous Egyptian standards (ES) No. 1589 of 2005 [61], as the recommended that bottled packaged drinking waters (other than natural mineral waters) must be fit for human consumption and should be completely free of protozoa that are harmful to health and any non-bacterial microorganisms (Table 6).

\section{The Treatment of Drinking Water}

Water quality control is a real challenge as water plays an important role in the transmission of parasite pathogens and making it more difficult that the most produce cysts, oocysts or eggs that are highly resistant to water disinfection and are difficult to remove some of them by filtration processes. However, parasite pathogens in drinking water can be greatly reduced by water treatments plants. The most effective way to remove or inactivation of protozoal cysts and oocysts is filtration with coagulation and flocculation followed by disinfectants [1]. Filtration acts as a stable and effective barrier for microbial pathogens. Rapid filtration does not effectively remove microbial pathogens while slow sand filters can be very effective in removing microbial contamination from water. However, diatom filtration has been shown to be more effective in reducing the concentration of Cryptosporidium oocytes and Giardia [62]. However, [63] did not ensure that filtered water was free of water-related protozoa. Therefore, high levels of disinfection or more effective disinfection procedures were necessary to protect humans from waterborne protozoa such as Cryptosporidium and Giardia [64]. Following filtration a disinfectant needs to be added to the water, and the ideal disinfectant must meet the following requirements: Effective in removing pathogens, produce a disinfectant residual, do not produce unwanted products, can be easily, safe to handle and suitable for large-scale use and be cost-effective. Not all disinfectants currently meet all these requirements. Chlorine remains the main chemical used for this purpose worldwide. It is a powerful disinfectant and 
Table 6. The maximum limit of Egyptian specifications in terms of parasites in potable bottled packaged drinking waters (other than natural mineral waters).

\begin{tabular}{cll}
\hline $\begin{array}{c}\text { Name of national } \\
\text { regulation }\end{array}$ & \multicolumn{1}{c}{ Maximum permissible limits issued by the Egyptian Organization for Standardization and Quality } \\
\cline { 2 - 3 } Egyptian Standards & $\begin{array}{l}\text { Bottled packaged drinking water should be free } \\
\text { from pathogenic microorganisms. }\end{array}$ & $\begin{array}{l}\text { Bottled packaged drinking water must be completely free } \\
\text { from pathogenic microorganisms and protozoa that are } \\
\text { harmful to health. }\end{array}$ \\
\hline ES: $1589 / 2005 ; 2007$ & & \\
\hline
\end{tabular}

effective in short contact times as well as easy to apply. Nevertheless, it has several disadvantages: ineffectiveness against protozoa, loss of effectiveness [65] [66]. Jarroll et al. [67] determined that Giardia cysts had been relatively resistant to chlorine inactivation. Cryptosporidium is one of the most resistant microorganisms in the water. Chloramines include monochloramine and dichloramine and although it is a weak antiseptic, it is still used. Increasing water contact with disinfection by storing it before providing consumers is important for more resistant microorganisms, such as giardiasis [1]. Chlorine dioxide is an effective disinfectant against Giardia and Cryptosporidium (about 90\% inactivation of cysts and oocysts), its biocidal efficacy is slightly higher than that of chlorine under certain conditions [68].

Ozonization and ultraviolet disinfection are used as additional methods of disinfection. When used in combination with chlorination, they increase its efficiency and reduce the number of chlorine-containing reagents added [69]. Water entering the distribution system must be microbially safe and ideally should also be biologically stable. Drinking-water entering the distribution system may contain free-living amoebae and under favorable conditions, amoebae may colonize distribution systems and form biofilms. Immuno-compromised people may be at risk of amoeba from biofilms with adverse health effects [1].

\section{Conclusion}

Access to safe drinking water is a fundamental human right. There is a need for safe drinking water to preserve life, maintain public health and reduce diseases. A growing concern globally after the scientists revealed the effects of polluted drinking water. It is estimated that more than $80 \%$ of diseases are caused by contaminated drinking water. This means that water is the main cause of most diseases, so, a large number of the population is at risk of water pollution, and for this, guidelines and standards for drinking water quality have been developed to ensure that people have access to safe drinking water. Drinking water quality guidelines and regulations are based on published scientific research on physical, chemical, biological and radiological aspects. The World Health Organization's drinking water quality guidelines are the international reference points for drinking water quality standards. These guidelines are not mandatory and therefore there may be differences in drinking water standards between different countries. In Egypt, law No. 27 of 1978 was issued on the public resources for drinking water and 
human use. The public resources for drinking water and human use act give the Ministry of Health and population the responsibility to set and enforce standards for drinking water. These standards apply to public water systems and must be legally enforceable. Minister of Health decree No. 108 of 1995 and decree No. (458) of 2007 were issued in this regard. These standards ensure the quality of drinking water in Egypt is safe for human consumption. Egyptian standards recommended that microbiological examination of drinking water samples should be completely free of live protozoa and all stages of pathogenic worms. In 2005, Presidential Decree No. 83 issued that the Egyptian Organization for Standardization and Quality is responsible for preparing and issuing standards for food products through technical committees according to international standards. Egyptian organization for standardization and quality issued the standard specifications for both potable bottled natural mineral water (ES: 1588/2005; 2017), and bottled packaged drinking waters (other than natural mineral waters) (ES: 1589/2005; 2007), to ensure the quality of both potable bottled natural mineral water and bottled packaged drinking waters (other than natural mineral waters), in Egypt is safe for human consumption. The Egyptian standard recommended that potable bottled natural mineral water should be free from primary organisms that pose a threat to health and specifically pathogenic microorganisms including parasites. Bottled packaged drinking water must be completely free from pathogenic microorganisms and protozoa that are harmful to health. Regarding microbiological standards in Egypt, The standards do not require specific parasite screening, as in the United States of America, which the US EPA requires Cryptosporidium and Giardia lamblia tests. In addition, the US EPA [70] recommends removing 99.9 percent of Cryptosporidium and Giardia lamblia before water consumption.

\section{Conflicts of Interest}

The author declares no conflicts of interest regarding the publication of this paper.

\section{References}

[1] WHO (2017) Guidelines for Drinking-Water Quality: Fourth Edition Incorporating the First Addendum. Geneva.

[2] Grandjean, A.C. (2004) Water Requirements, Impinging Factors, \& Recommended Intakes. World Health Organization, Geneva, 25-34.

[3] UN News (2010) Unsafe Water Kills More People than War, Ban Says on World Day.

[4] WHO (2018) Drinking-Water.

[5] Schardt, D. (2000) Water, Water Everywhere. Center for Science in the Public Interest, Washington DC.

[6] Hall, E.L. and Dietrich, A.M. (2000) A Brief History of Drinking Water. American Water Works Association, Washington DC, Product No. OPF-0051634.

[7] WHO (2014) Progress on Drinking Water and Sanitation: 2014 Update. World 
Health Organization and United Nations Children's Fund, Geneva.

[8] Donia, N. (2007) Survey of Potable Water Quality Problems in Egypt. 11 th International Water Technology Conference, Alexandria, 1049-1058.

[9] Geriesh, M.H., Balke, K.D. and El-Rayes, A.E. (2008) Problems of Drinking Water Treatment along Ismailia Canal Province, Egypt. Journal of Zhejiang University Science B, 9, 232-242. https://doi.org/10.1631/jzus.B0710634

[10] Zwane, A.P. and Kremer, M. (2007) What Works in Fighting Diarrheal Diseases in Developing Countries? A Critical Review. The World Bank Research Observer, 22, 1-24. https://doi.org/10.1093/wbro/lkm002

[11] Bartram, J. and Cairncross, S. (2010) Hygiene, Sanitation, and Water: Forgotten Foundations of Health. PLOS Medicine, 7, e1000367. https://doi.org/10.1371/journal.pmed.1000367

[12] Fewtrell, L., Kaufmann, R.B., Kay, D., Enanoria, W., Haller, L. and Colford, J.M.J. (2005) Water, Sanitation, and Hygiene Interventions to Reduce Diarrhoea in Less Developed Countries: A Systematic Review and Meta-Analysis. The Lancet Infectious Diseases, 5, 42-52. https://doi.org/10.1016/S1473-3099(04)01253-8

[13] Clasen, T., Schmidt, W.P., Rabie, T., Roberts, I. and Cairncross, S. (2007) Interventions to Improve Water Quality for Preventing Diarrhoea: Systematic Review and Meta-Analysis. BMJ, 334, 782. https://doi.org/10.1136/bmj.39118.489931.BE

[14] Waddington, H. and Snilstveit, B. (2009) Effectiveness and Sustainability of Water, Sanitation, and Hygiene Interventions in Combating Diarrhoea. Journal of Development Effectiveness, 1, 295-335. https://doi.org/10.1080/19439340903141175

[15] Cairncross, S., Hunt, C., Boisson, S., Bostoen, K., Curtis, V., Fung, I.C. and Schmidt, W.P. (2010) Water, Sanitation and Hygiene for the Prevention of Diarrhoea. International Journal of Epidemiology, 39, i193-i205. https://doi.org/10.1093/ije/dyq035

[16] Fink, G., Günther, I. and Hill, K. (2011) The Effect of Water and Sanitation on Child Health: Evidence from the Demographic and Health Surveys 1986-2007. International Journal of Epidemiology, 40, 1196-1204.

https://doi.org/10.1093/ije/dyr102

[17] Abou-Ali, H. (2015) The Effect of Water and Sanitation on Child Mortality in Egypt. University of Göteborg, School of Business, Economics and Law, Göteborg. https:/gupea.ub.gu.se/bitstream/2077/2828/1/gunwpe0112.pdf

[18] Fuentes, R., Pfütze, T. and Seck, P. (2006) Does Access to Water and Sanitation Affect Child Survival? A Five Country Analysis. Human Development Report Office, United Nations Development Programme, New York, Report No. 2006/4.

[19] United Nations Water (2017) WHO/UNICEF Joint Monitoring Programme 2017 Report.

[20] Godfree, A. and Godfrey, S. (2008) Water Reuse Criteria: Environmental and Health Risk Based Standards and Guidelines. In: Jimenez, B. and Asana, T., Eds., Water Reuse: An International Survey of Current Practice, Issues and Needs, IWA Publishing, London, 351-369.

[21] EPA (2017) Drinking Water Contaminants-Standards and Regulations. EPA 822-F-18-001, Office of Water U.S. Environmental Protection Agency, Washington DC.

[22] WHO (2004) Guidelines for Drinking-Water Quality. Vol. 1, Recommendations. 3rd Edition, Geneva.

[23] WHO (1985) Guidelines for Drinking-Water Quality. Vol. 1, Drinking-Water Quality Control in Small-Community Supplies. Geneva. 
[24] CDC (2016) Parasites. CDC 24/7: Saving Lives, Protecting People. Centers for Disease Control and Prevention, U.S. Department of Health \& Human Services.

[25] Theresa, R.S., Joan, V.S. and Rose, B. (2000) Emerging Parasite Zoonoses Associated with Water and Food. International Journal for Parasitology, 30, 1379-1393. https://doi.org/10.1016/S0020-7519(00)00128-4

[26] Cox, F.E.G. (2002) History of Human Parasitology. Clinical Microbiology Reviews, 15, 595-612. https://doi.org/10.1128/CMR.15.4.595-612.2002

[27] Taher, E.E., Méabed, E.M.H., Abdallah, I. and Abdel Wahed, W.Y. (2018) Acanthamoeba Keratitis in Noncompliant Soft Contact Lenses Users: Genotyping and Risk Factors, a Study from Cairo, Egypt. Journal of Infection and Public Health, 11, 377-383. https://doi.org/10.1016/j.jiph.2017.09.013

[28] Elfadaly, H.A., Hassanain, N.A., Hassanain, M.A., Barakat, A.M. and Shaapan, R.M. (2018) Evaluation of Primitive Ground Water Supplies as a Risk Factor for the Development of Major Waterborne Zoonosis in Egyptian Children Living in Rural Areas. Journal of Infection and Public Health, 11, 203-208.

https://doi.org/10.1016/j.jiph.2017.07.025

[29] Abd El Wahab, W.M., El-Badry, A.A. and Hamdy, D.A. (2018) Molecular Characterization and Phylogenetic Analysis of Acanthamoeba Isolates in Tap Water of Beni-Suef, Egypt. Acta Parasitologica, 63, 826-834. https://doi.org/10.1515/ap-2018-0101

[30] El-Badry, A.A., Hamdy, D.A. and Abd El Wahab, W.M. (2018) Strongyloides Stercoralis Larvae Found for the First Time in Tap Water Using a Novel Culture Method. Parasitology Research, 117, 3775-3780. https://doi.org/10.1007/s00436-018-6078-1

[31] Radwan, E.H., Hassan, A.A., Lotfy, W.M., Abd El-Mawgood, A. and Mashaal, H.M. (2019) The Prevalence of Intestinal Parasite Infection in El Behara School Children. International Journal of Limnology, 1, 33-51.

[32] Shehata, A.I., Hassanein, F. and Abdul-Ghani, R. (2019) Opportunistic Parasitoses among Egyptian Hemodialysis Patients in Relation to CD4+ T-Cell Counts: A Comparative Study. BMC Infectious Diseases, 19, 480. https://doi.org/10.1186/s12879-019-4110-4

[33] El-Badry, A.A., Abu-Sarea, E.Y., Mahmoud, A.H., Ghieth, M.A. and Ismail, M.A.M. (2019) The First Entamoebamoshkovskii Molecular Detection in Egypt. Comparative Clinical Pathology, 28, 501-504. https://doi.org/10.1007/s00580-018-2878-z

[34] El-Shazly, A.M., Awad, S.E., Sultan, D.M., Sadek, G.S., Khalil, H.H. and Morsy, T.A. (2006) Intestinal Parasites in Dakahlia Governorate with Different Techniques in Diagnosing Protozoa. Journal of the Egyptian Society of Parasitology, 36, 1023-1034.

[35] Khalifa, R.M.A., Azza, K., Ahmad, A.K., Abdel-Hafeez, E.H. and Mosllem, A.A. (2014) Present Status of Protozoan Pathogens Causing Water-Borne Disease in Northern Part of EL-Minia Governorate, Egypt. Journal of the Egyptian Society of Parasitology, 44, 559-566. https://doi.org/10.12816/0007860

[36] Amer, A.S. (2012) Monitoring for the Presence of Parasitic Protozoa and Free-Living Amoebae in Drinking Water Plants. Journal of Natural Resources and Development, 2, 15-21.

[37] Elshazly, A.M., Elsheikha, H.M., Soltan, D.M., Mohammad, K.A. and Morsy, T.A. (2007) Protozoal Pollution of Surface Water Sources in Dakahlia Governorate, Egypt. Journal of the Egyptian Society of Parasitology, 37, 51-64.

[38] Attia, R.H., Tolba, M.E.M., Yones, D.A., Bakir, H.Y., Eldeek, H.E.M. and Kamel, S. 
(2012) Capillaria philippinensis in Upper Egypt: Has It Become Endemic? The American Journal of Tropical Medicine and Hygiene, 86, 126-133. https://doi.org/10.4269/ajtmh.2012.11-0321

[39] Miller, F.D., Hussein, M., Mancy, K.H. and Hilbert, M.S. (1980) Human Intestinal Parasitic Infections and Environmental Health Factors in Rural Egyptian Communities: A Report of the U.S.-Egyptian River Nile and Lake Nasser Research Project. Environmental Research Laboratory Office of Research and Development U.S. Environmental Protection Agency, Athens.

[40] Abaza, H., El-Zayadi, A., Kabil, S.M. and Rizk, H. (1998) Nitazoxanide in the Treatment of Patients with Intestinal Protozoan and Helminthic Infections: A Report on 546 Patients in Egypt. Current Therapeutic Research, 59, 116-121. https://doi.org/10.1016/S0011-393X(98)85006-6

[41] Abdel Mawla, M.M. (1990) Ultrastructure of the Cyst Wall of $S$. lindemanni with Pathological Correlations. Journal of the Egyptian Society of Parasitology, 20, 319-325.

[42] Abdel-Hafeez, E.H., Ahmad, A.K., Ali, B.A. and Moslam, F.A. (2012) Opportunistic Parasites among Immunosuppressed Children in Minia District, Egypt. The Korean Journal of Parasitology, 50, 57-62. https://doi.org/10.3347/kjp.2012.50.1.57

[43] Youssef, F.G., Mikhail, E.M. and Mansour, N.S. (1989) Intestinal Capillariasis in Egypt: A Case Report. The American Journal of Tropical Medicine and Hygiene, 40, 195-196. https://doi.org/10.4269/ajtmh.1989.40.195

[44] El Sharazly, B.M., AbouRayia, D.M., Antonios, S.N. and Eissa, S.H. (2016) Current Status of Schistosoma mansoni Infection and Its Snail Host in Three Rural Areas in Gharbia Governorate, Egypt. Tanta Medical Journal, 44, 141-150. https://doi.org/10.4103/1110-1415.201724

[45] El-Sahly, A.M., Zakaria, S., Ahmed, L., Mabrouk, M.A., Thakeb, F., Zakaria, M.S., Farrag, A.E. and Goldsmith, R.S. (1990) Intestinal Helminthic and Protozoal Infections and Urinary Schistosomiasis in Egyptian Children. Journal of the Egyptian Society of Parasitology, 20, 9-21.

[46] Abdo, B.R.N., Sayed, A.S.M., Hussein, A.A.A. and Arafa, M.I. (2012) Occurrence of Taenia solium and Cysticercosis in Man in Egypt. Veterinary World, 3, 57-60.

[47] Marciano-Cabral, F. and Cabral, G. (2007) The Immune Response to Naegleria fowleri Amebae and Pathogenesis of Infection. External Icon. FEMS Immunology and Medical Microbiology, 51, 243-259.

https://doi.org/10.1111/j.1574-695X.2007.00332.x

[48] CDC (2019) Parasites-Naegleria fowleri-Primary Amebic Meningoencephalitis (PAM)-Amebic Encephalitis. CDC 24/7: Saving Lives, Protecting People. Centers for Disease Control and Prevention, CDC.gov. U.S. Department of Health \& Human Services, Atlanta.

[49] Baig, A.M., Zuberi, H. and Khan, N.A. (2014) Recommendations for the Management of Acanthamoeba Keratitis. Journal of Medical Microbiology, 63, 770-771. https://doi.org/10.1099/jmm.0.069237-0

[50] Marciano-Cabral, F. and Cabral, G. (2003) Acanthamoeba spp. as Agents of Disease in Humans. Clinical Microbiology Reviews, 16, 273-307. https://doi.org/10.1128/CMR.16.2.273-307.2003

[51] Tischler, S.R. (2007) Drinking Water Regulations \& Standards: An International Perspective. Water Quality Products Magazine.

[52] Pontius, F.W. and Clark, S.W. (1999) Chapter 1, Drinking Water Quality Standards, Regulations and Goals. In: Letterman, R.D., Ed., Water Quality and Treatment, 
Fifth Edition, American Water Works Association, McGraw-Hill, Inc., New York.

[53] EPA (2018) 2018 Edition of the Drinking Water Standards and Health Advisories. EPA 822-F-18-001 Office of Water U.S. Environmental Protection Agency, Washington DC.

[54] WHO (2006) Guidelines for Drinking-Water Quality. Incorporating First Addendum. Vol. 1, Recommendations. 3rd Edition, Geneva.

[55] Minister of Health and Population (1995) Egyptian Standard Specifications for Potable Drinking Water. Decision of the Minister of Health and Population No. 108, Cairo.

[56] Minister of Health and Population (2007) Egyptian Standard Specifications for Potable Drinking Water. Decision of the Minister of Health and Population No. 458, Cairo.

[57] SDWF (2019) Bottled Water. Safe Drinking Water Foundation (SDWF), Saskatoon, Canada.

[58] Egyptian Standards (ES, 1588/2005). The Egyptian Organization for Standardization and Quality Control (EOS). Decree No. 1588/2005 for Standards of Potable Bottled Natural Mineral Water.

[59] Egyptian Standards (ES, 1588/2017). The Egyptian Organization for Standardization and Quality Control (EOS). Decree No. 1588/2017 for Standards of Potable Bottled Natural Mineral Water.

[60] Egyptian Standards (ES, 1589/2007). The Egyptian Organization for Standardization and Quality Control (EOS). Decree No. 1589/2007 for Standards of Botteled/Packaged Drinking Waters (Other than Natural Mineral Waters).

[61] Egyptian Standards (ES, 1589/2005). The Egyptian Organization for Standardization and Quality Control (EOS). Decree No. 1589/2005 for Standards of Botteled/Packaged Drinking Waters (Other than Natural Mineral Waters).

[62] Ongerth, J.E. and Hutton, P.E. (2001) Testing of Diatomaceous Earth Filtration for Removal of Cryptosporidium Oocysts. Journal-American Water Works Association, 93, 54-63. https://doi.org/10.1002/j.1551-8833.2001.tb09355.x

[63] Le Chevallier, M.W., Norton, M.W. and Lee, R.G. (1991) Giardia and Cryptosporidium spp. in Filtered Drinking Water Supplies. Applied and Environmental Microbiology, 57, 2610-2616.

[64] Van der Bruggen, B., Vandecasteele, C., Gestel, T.V., Doyen, W. and Leysen, R. (2003) A Review of Pressure-Driven Membrane Processes in Wastewater Treatment and Drinking Water Production. Environmental Progress, 22, 46-56. https://doi.org/10.1002/ep.670220116

[65] Arnold, B.F. and Colford, J.M. (2007) Treating Water with Chlorine at Point-of-Use to Improve Water Quality and Reduce Child Diarrhea in Developing Countries: A Systematic Review and Meta-Analysis. The American Journal of Tropical Medicine and Hygiene, 76, 354-364. https://doi.org/10.4269/ajtmh.2007.76.354

[66] Medeiros, R.C. and Daniel, L.A. (2015) Study of Sequential Disinfection for the Inactivation of Protozoa and Indicator Microorganisms in Wastewater. Acta Scientiarum: Technology, 37, 203-209. https://doi.org/10.4025/actascitechnol.v37i2.24950

[67] Jarroll, E.L., Bingham, A.K. and Meyer, E.A. (1981) Effect of Chlorine on Giardia lamblia Cyst Viability. Applied and Environmental Microbiology, 41, 483-487.

[68] Cotruva, J.A., Durfour, A., Rees, G., Bartram, J., Carr, R., Cliver, D.O., Craun, G.F., Fayer, R. and Gannon, V.P.J. (2004) Waterborne Zoonoses: Identification Causes 
and Control. World Health Organization, IWA Publishing, London, 255-282.

[69] Betancourt, W.Q. and Rose, J.B. (2004) Drinking Water Treatment Processes for Removal of Cryptosporidium and Giardia. Veterinary Parasitology, 126, 219-234. https://doi.org/10.1016/j.vetpar.2004.09.002

[70] United States Environmental Protection Agency (2018) Edition of the Drinking Water Standards and Health Advisories Tables. EPA 822-F-18-001. Office If Water U.S. Environmental Protection Agency, Washington DC. 